\title{
THE DEVELOPMENT OF NEUROTECHNOLOGIES IN THE PERIOD OF THE SIXTH TECHNO-LOGICAL ORDER
}

\author{
Valery V. Glushchenko ${ }^{* 1}$ 西 (iD \\ ${ }^{* 1}$ Doctor of Technical Sciences, Associate Professor, Professor of the Project Activity Center \\ Moscow Polytechnic University, Moscow, Russia
}

DOI: https://doi.org/10.29121/IJOEST.v5.i2.2021.163

Article Type: Research Article

Article Citation: Valery V. Glushchenko. (2021). THE

DEVELOPMENT OF

NEUROTECHNOLOGIES IN THE

PERIOD OF THE SIXTH TECHNO-

LOGICAL ORDER. International

Journal of Engineering Science

Technologies, 5(2), 45-57.

https://doi.org/10.29121/IJOEST.v

5.i2.2021.163

Received Date: 10 February 2021

Accepted Date: 20 March 2021

Keywords:

Neurotechnology

Sixth Technological Order

Machine-Building

Development

Structure

Meth-Odology

Principle

Function

Role

Analysis

Synthesis

Efficiency

Evaluation

Criterion

\begin{abstract}
The subject of the article is the development of neurotechnologies in the sixth technological or-der, the object of the article is neurotechnologies, the purpose of the work is to increase the ef-ficiency of the development of neurotechnologies in the sixth technological order, to achieve this goal, the following tasks are solved: research of the concept, content, structural elements of the sixth technological order; description of the essence and content of neurotechnologies; de-velopment of methods of logical analysis and synthesis of neurotechnologies; the scientific methods in the article are forecasting, synthesis and analysis, historical and logical analysis, expert assessments, comparative and system analysis; the scientific novelty of the article is as-sociated with the formation of the methodology for the development of neurotechnologies in the period of the sixth technological order.
\end{abstract}

\section{INTRODUCTION}

The relevance of the article in 2021 is determined by the creation of a roadmap for the development of nanotechnology in Russia. This roadmap was developed within the framework of the National technology initiative of Russia. This roadmap was developed in the interests of forming the sixth technological order. This roadmap should create an increase in the competitiveness of the domestic engineering industry. 
The hypothesis of the article: the competitiveness of mechanical engineering can be increased by developing the segment of neurotechnological engineering. The development of power engineering will lead to an increase in the influence of neurotechnologies on global markets.

The purpose of the article is to increase the efficiency of the processes of development of neurotechnologies in the period of the sixth technological order.

To achieve this goal, the following tasks are solved:

- research of the concept, content, and structural elements of the sixth technological order in post-industrial engineering;

- description of the essence and content of neurotechnologies in post-industrial engineering;

- development of methods of logical analysis and synthesis of neurotechnologies in post-industrial mechanical engineering,

- formation of the criteria base for evaluating the effectiveness of the processes of development of neurotechnological engineering in the framework of the sixth technological order.

The object of the article is neurotechnologies.

The subject of the work is the methodology of the development of neurotechnologies in the period of the sixth technological order.

At the beginning of the 21st century, there is a transition to the sixth technological order [1], p. 488-504; [2], p. 3-29]. In this article, we will understand the technological structure as a system combination of: technologies (the technological basis of organizations); industrial social relations (institutions); forms of doing business; management methods in the economy [2], p. 3-29].

The basis of the sixth technological order will be: nanotechnologies; biotechnologies; neurotechnologies; digitalization technologies; information technologies; resource-saving technologies; environmentally friendly technologies.

The key achievement of this technological order (as predicted) can be: individualization of production items; individualization of production and consumption processes; intensive reduction of material and energy intensity of industrial production processes; creation of materials and goods with the projected properties and characteristics.

The humanitarian consequences of the development of the sixth technological order (according to known forecasts) can be: a significant improvement in the quality of life. The increase in the quality of life will be accompanied by an increase in the life expectancy of humans and animals.

According to expert estimates in the most developed countries in 2010 there was such a ratio of technologies:

- technologies related to the fifth technological order were about $60 \%$;

- the technologies of the fourth mode were about $20 \%$;

- the share of technologies of the sixth technological order was close to $5 \%$.

It is predicted that developed countries may enter the sixth technological order at the end of the second decade of the 21st century.

In this regard, research is being actively conducted: the influence of neuro-technologies on innovation activity is being studied [3], p. 17-22]; the impact of neurotechnologies on the development of the entire national economy [4], p. 244-247 ]. Experts talk about the need for the development of neuroscience in order to study neuroeconomics [5], p. 71-75]. Neuroeconomics is recognized as a new com-plex method of studying the behavior of economic entities [6], p. 188-199].

At the same time, it is nanotechnology that is considered as the main compo-nent of the sixth technological order [7], p.16-21].

In connection with the prospect of transition to the sixth technological order in the industry, researchers are engaged in: structural forecasting and studying the priorities of industrial development [8], p. 182-189]; studying the features of managing the development of high-tech organizations [9], p.729-734]; analyzing the impact of the sixth technological order on the regional economy [10], p. 247-251]; studying the features of personnel management [11], p. 84-86]. 
The analysis of the results of research on the development of the sixth technological order presented in this article shows the following. Neurotechnologies are not considered as a structural element of the sixth technological order. Therefore, neurotechnologies are not yet included in the structure of the sixth technological order.

The technological structure of the sixth technological order is called: the main technologies of this order; the connections between these technologies.

This article proposes to include the development of neurotechnologies in the structure of the sixth technological order. Neurotechnologies should become one of the main structural elements of the sixth technological order. The basis for such a proposal may be the following. It is known that neuroeconomics and neuromarketing are already quite developed. Neuromarketing is considered as a tool for managing the development of organizations [12], p. 30]. Neurotechnologies are recognized as having a great future [13], p. 220-234]. Researchers believe that neurotechnologies provide an opportunity to reduce the workload on employees [14], p. 43-47]. Therefore, the development of nanotechnology will lead to an improvement in the quality of working life. This will lead to an increase in the quality and duration of human life.

Neurotechnologies can be used to analyze complex situations in the development of large systems [15], p. 409412]. Therefore, neurotechnologies can influence the process of development and formation of the sixth technological order in the economy and, in particular, in mechanical engineering.

Neurotechnologies can be used in making managerial decisions under conditions of uncertainty [16], p. 173176]. Therefore, the development of nanotechnology can contribute to solving the problem of increasing the efficiency of public production. Neurotechnologies can increase the efficiency and safety of the use of natural resources [17], p. 6-12]. Therefore, neurotechnologies can play an important role in the new industrial development [18], p. 82-85]. The development of neurotechnologies contributes to the modification of social feedbacks [19], p. 21-23]. Neurotechnologies influence the social and cultural space [20], p. 183-187]. Neurotechnologies help to make changes in the work of development institutions in the formation of the sixth technological order [1], p. 3-29]. Neurotechnologies can influence the development of the sixth technological order. This is due to their large role in the development of the digital economy [21], p. 35-38].

Neurotechnologies can be considered as an object of activity and development of new industrial branches [22], p. 393-400]. Neurotechnologies are part of the branches of the digital economy [23], p. 3269-3278]. The introduction of neurotechnologies in education is expected [24], p. 205-207]. At the same time, education is considered as an important tool for the formation of the sixth technological order.

Thus, the materials of this article allow us to conclude that there are grounds for including neurotechnologies in the structure of the sixth technological order.

However, the development of neurotechnologies is not only promising, but also involves significant risks [25], p. 249-250].

We need indicators to assess the level of development of neurotechnologies in the national economy. An indicator that reflects the country's place in the market of such technologies can be proposed [26], p. 14-18]. An indicator equal to the percentage of the country's neurotechnology market can also be used. The country's place in the ranking of the most developed countries in this direction can be considered.

At the same time, the analysis of the prospects for the development of neurotechnologies is of great importance [27], p.142-151]. This value applies not only to neurotechnological development, but also to the development of the sixth technological order as a whole.

In particular, the roadmap for such development can play an important role in the development of neurotechnologies in our country.

The roadmap for the development of neurotechnologies defines these technologies. Neurotechnologies are defined as technologies that: are based on understanding the work of the human brain; help to understand the work of the human brain; study the higher nervous activity of a person. Neurotechnologies also include technologies that: enhance and improve the functioning of the human brain; technologies that improve the mental activity of a person [28].

\section{METHOD}

Studies of neuromarketing (which acts as a structural element of neurotechnologies) show that a broader definition of neurotechnologies is possible [29], p. 201-212; 28, p.182-192]. 
In this article, neurotechnology is proposed to be understood as a systematic combination of initial resources, methods and tools of activity, and personnel qualification skills. Neurotechnologies should make it possible to synthesize products (goods and services) that are characteristic of the sixth technological order. These products should increase the efficiency and / or safety of human activity.

At the same time, a specific feature of neurotechnology can be recognized as the use in neurotechnology: knowledge about the higher nervous activity of a person; the results of physical measurements of human reactions to external factors; a game approach in learning and mastering skills.

The results of the research allow us to recognize the field of application of neurotechnologies [29], p. 201-212; [30], p. 182-192]:

1) the study of higher nervous activity and / or biological reactions of a person to external stimuli. Such research is carried out in the interests of: better understanding and / or assistance in understanding the work of the brain, higher nervous activity; in the interests of creating devices and systems aimed at improving the efficiency and sustainability of social and economic development;

2) the study of paradoxical human behavior in the processes of social and economic development (neuroeconomics and neurosociology). Paradoxical behavior is studied in the interests of using the knowledge gained in creating systems that limit the damage from such behavior;

3) the formation of training programs and systems based on the game approach to learning. The game approach allows you to improve the quality of professional training and education, etc.

Neurosociology (by analogy with neuroeconomics) in this article, we propose to call a part of sociology. The object of neurosociology research is the illogical, paradoxical behavior of people in social and industrial relations, in particular, in situations of stress.

At the same time, the development of scientific support for neurotechnologies should be developed within the framework of the general scientific support for innovation activities [31], p.5].

The mechanism of influence of neurotechnologies on the development of the sixth technological order in postindustrial engineering will be called a set of methods, methods and tools used in the process of such development.

In this article, post-industrial neurotechnological mechanical engineering is proposed to mean a special sector of high-tech mechanical engineering. In this sector, the philosophy and organizational culture of functioning are focused on the synthesis of devices that implement neurotechnologies. Based on the results of scientific and technological progress of new needs, this synthesis is aimed at meeting new (or previously hidden - latent) needs of the economy and society in the products of neurotechnological engineering. These products are based on the development and practical application of neurotechnologies.

When studying the impact of neurotechnologies on the formation of the sixth technological order in postindustrial engineering, it is recommended to take into account the following. Research shows that over a long period of time, the risks of innovation remain high. According to Philip Kotler, the risks of innovation activity (depending on the type of market) are in the range of 18-40\% [32], p.288]. At the same time, the average share of unsuccessful innovative projects over the previous decades (in Japan and the UK) ranged from $40 \%$ to $60 \%$ [33], p. 456-465; [34], p. 848-856; [35], p. 37- 46].

The development of neurotechnologies within the framework of the sixth technological order takes place against the background of the formation of a post-industrial approach in marketing [36], p.6-13]. Post-industrial marketing focuses on creating new needs for customers. Then the new needs are met by introducing the achievements of scientific and technological progress. Neurotechnologies are such an achievement of scientific and technological progress in the sixth technological order.

The organizational feature of the development of neurotechnologies in the conditions of the sixth technological order can be called the formation of technological and scientific platforms [37].

At the same time, the method of forming a strategy for the transition to the sixth technological order is described in [38]; p.37; [39], p. $30-46]$.

To assess the possibility of introducing neurotechnologies (and other technologies of the sixth technological order in the organization's products, a special table can be developed. Such a table can be called the table of implementation (animation) of neurotechnologies in the products of the enterprise. Such tables can be developed at a specific enterprise for each type of product. Such studies are carried out in the interests of determining the possibility (and subsequently the economic feasibility) of applying the technologies of the new technological order in the products of the previous technological order.

International Journal of Engineering Science Technologies 
The rows of such a table can correspond to the numbers of technological orders. The numbers of technological orders determine the profile products of these orders. The columns of this table are added: numbers in order; numbers of technological orders; elements of neurotechnologies. The elements of neurotechnology are divided into three parts: recording human reactions; determining the variants of illogical human behavior; and using the game approach in training. The intersection of the row and column describes the direction of using neurotechnologies in the products of previous technological orders (Table 1).

Table 1: Directions of introduction of elements of neurotechnologies in products of the previous technological orders

\begin{tabular}{|c|c|c|c|c|c|}
\hline $\begin{array}{l}\text { № } \\
\text { п/п }\end{array}$ & $\begin{array}{l}\text { Names, time } \\
\text { period of the } \\
\text { technological } \\
\text { order }\end{array}$ & $\begin{array}{c}\text { Typical } \\
\text { products of the } \\
\text { technological } \\
\text { order }\end{array}$ & $\begin{array}{l}\text { Element of } \\
\text { neurotechnology: } \\
\text { registration of } \\
\text { human reactions }\end{array}$ & $\begin{array}{c}\text { The element of } \\
\text { neuro-technology: } \\
\text { the study of } \\
\text { illogical human } \\
\text { behavior }\end{array}$ & $\begin{array}{c}\text { The element of } \\
\text { neurotechnology: a } \\
\text { game-based approach } \\
\text { to learning }\end{array}$ \\
\hline$(1)$ & $(2)$ & (3) & (4) & $(5)$ & (6) \\
\hline 1. & $\begin{array}{c}\text { Electric motor, } \\
\text { 1880-1930 } \\
\text { ' } \\
\text { The third } \\
\text { technological } \\
\text { order (mode), }\end{array}$ & $\begin{array}{c}\text { Trolleybus, } \\
\text { lathe, telephone }\end{array}$ & $\begin{array}{l}\text { Registration of } \\
\text { reactions of the } \\
\text { trolleybus driver } \\
\text { (turner) }\end{array}$ & $\begin{array}{l}\text { Evaluation of } \\
\text { options for } \\
\text { illogical behavior } \\
\text { of a trolleybus } \\
\text { driver in an } \\
\text { emergency } \\
\text { situation }\end{array}$ & $\begin{array}{c}\text { Organization of game } \\
\text { training of the } \\
\text { trolleybus driver }\end{array}$ \\
\hline 2. & $\begin{array}{c}\text { Internal } \\
\text { combustion } \\
\text { engine, } \\
\text { 1930-1970, } \\
\text { Fourth } \\
\text { technological } \\
\text { order, }\end{array}$ & $\begin{array}{l}\text { Bus, plane, } \\
\text { diesel } \\
\text { locomotive }\end{array}$ & $\begin{array}{l}\text { Registration of bus } \\
\text { driver (pilot) } \\
\text { reactions }\end{array}$ & $\begin{array}{c}\text { Analysis of } \\
\text { variants of } \\
\text { illogical behavior } \\
\text { of a bus driver in a } \\
\text { non-standard } \\
\text { situation }\end{array}$ & $\begin{array}{c}\text { Organization of game } \\
\text { training of the bus } \\
\text { driver }\end{array}$ \\
\hline 3. & $\begin{array}{l}\text { Microelectronics } \\
\text { 1970-2010, } \\
\text { The fifth } \\
\text { technological } \\
\text { order, }\end{array}$ & $\begin{array}{c}\text { Flexible } \\
\text { automated } \\
\text { production, } \\
\text { mobile phone, } \\
\text { ATM, } \\
\text { plastic bank } \\
\text { card }\end{array}$ & $\begin{array}{l}\text { Registration of } \\
\text { reactions of the } \\
\text { operator of flexible } \\
\text { automated } \\
\text { production }\end{array}$ & $\begin{array}{l}\text { study of variants } \\
\text { of illogical } \\
\text { behavior of the } \\
\text { operator of } \\
\text { flexible automated } \\
\text { production in a } \\
\text { situation of stress }\end{array}$ & $\begin{array}{c}\text { A game-based } \\
\text { approach to training } \\
\text { the operator of } \\
\text { flexible automated } \\
\text { production }\end{array}$ \\
\hline
\end{tabular}

Source: developed by the author

The driving motive for the introduction of neurotechnologies in mechanical engineering of the sixth technological order can be:

- creation of new markets for neurotechnological engineering products within the framework of the sixth technological order;

- the desire to reduce the risks of innovative projects and thus increase the financial results of its activities.

- The tasks of using neurotechnologies in the process of forming the sixth technological order in mechanical engineering are:

- increasing the efficiency of machine-building corporations. This task is relevant at all stages of the life cycle of mechanical engineering products. The solution to this problem involves the formation of more effective competitive strategies in the markets;

- increase in the accuracy of information. This task includes knowledge of: the motives of buyers; the processes of making decisions by buyers about the purchase of goods of neurotechnological engineering; improving the methods of trade neuromarketing; 
- increasing the economic efficiency of management decisions. We are talking about management decisions in the process of designing new samples of mechanical engineering products (research neurotechnologies) and more.

The methodological basis for the development of neurotechnologies within the framework of the sixth technological order can be the scientific theory of the development of neurotechnologies (neurotechnology). This theory will create a methodological basis for the development of neurotechnological engineering. Neurotechnological machine building will become a new direction in mechanical engineering of the sixth technological order. The general theory of neurotechnology should reflect the essence of neurotechnology. This theory must realize its functions and roles. These functions and roles can be described by analogy with the methodological guidelines of the work [31], p. 5].

The cognitive (epistemological) significance of the general theory of neurotechnology will be determined by its ability to increase the effectiveness of scientific research in this area. The theoretical tasks of the general theory of neurotechnologies were described in [31], p. 5].

The practical role of a complete theory of neurotechnology may be as follows:

1) creation of a new market - the market of products of neurotechnological engineering (creation of neurotechnological engineering);

2) increase of financial results of economic activity of machine-building corporations on the basis of application of management neurotechnologies;

3) development and refinement of the description of the object of activity, the formation of a neurotechnological platform, and others.

Based on the structuring of the results of the study of neurotechnologies, the following tasks of the general theory of neurotechnologies can be determined:

- finding the most promising aspects of neurotechnological practice and science;

- synthesis of new technologies for the design and production of neuro-technological engineering products (goods and services);

- definitions of legal provisions for the practical application of neurotechnologies. At the same time, the rights of individuals and legal entities must be taken into account;

- formation of scientific knowledge for the development of technological platforms in the field of energy technology engineering;

- scientific substantiation of the characteristics of the innovative infrastructure for the development of energy-technological engineering;

- integrating the efforts of science, practice, and education to address the scientific development of the neurotechnology platform.

- The mission of the development of neurotechnologies can be considered to increase the efficiency of social production.

At the same time, the requirement to minimize the possibility of unfair use of neurotechnologies should be taken into account. In particular, it is important to exclude the possibility of manipulating people with the use of neuro technologies.

The structural elements of the development of neurotechnologies are the following areas: trade neuromarketing; managerial neuromarketing; neurotechnological management; neurotechnologies in the field of scientific and research work, and others.

The vision of the development of neuromachine engineering within the framework of the sixth technological order can be called the scenario of the development of neurotechnologies that inspires the subjects of this process. The subjects of this process are inventors, investors, scientists, and managers of enterprises.

Investors will be attracted by the rapid growth in the cost of capital. In addition, investors will be motivated by an honorable place in the hierarchy of innovative entrepreneurship. Scientists will be motivated by the possibility of new scientific discoveries in the research process. To do this, you need to register the copyright. There should be a possibility of receiving remuneration, prestigious scientific titles. Managers should be motivated by the rapid 
increase in the segment of neurotechnological engineering. The development of neurotechnological engineering will create prospects for rapid career growth of managers.

The content and essence of managerial and trade neuromarketing were studied in the works [29], pp. 201-212; [30], pp. 182-192].

Research neurotechnologies in mechanical engineering of the sixth technological order can solve such tasks:

- analytical tasks. These tasks consist in the registration and use of technical means of indicators of the state of people. These states are recorded taking into account the current external situation. The results of registration reflect a person's subjective perception of objective indicators of processes;

- creative tasks (tasks of the product and production character). These tasks include the design of neurotechnological technical devices. This task can also include the creation of services with the use of neurotechnologies. At the same time, problems of optimizing the characteristics of goods can be solved;

- the task of maximizing sales. This task will cover the creation of a new customer need using neurotechnologies. This task may include the development of a product promotion strategy;

- formative task. This task is to create motivation for the active use of research neurotechnologies in the activities of organizations (corporations);

- management task of neurotechnologies. This task of neurotechnologies is to increase the efficiency of the use of resources in the activities of organizations. For this purpose, neurotechnologies are used in the performance of all management functions in the organization (planning, organization, motivation, control).

- The roles of research neurotechnologies in machine-building corporations of the sixth technological order can be considered as:

- the formation of a new market segment for goods and services in machine-building of the sixth technological order (neuromachine-building). At the same time, there is a prospect of increasing the production of neurotechnological devices. New needs may arise. It will be required to meet the existing and potential (latent) demand for neurotechnological goods and services;

- increasing the competitiveness of organizations engaged in the development of neurotechnologies;

- growth of financial results of research, production, and trading activities of energy-technology engineering firms;

- reducing the likelihood of negative consequences of risks. Neuro technologies in management can reduce risks. This will reduce the damage caused by managers ' mistakes.

The philosophy of the development of research neurotechnologies will be the most general, wise view of: the need for the use of neurotechnologies in scientific, innovative activities, development work in engineering firms; the use of neurotechnologies in the interests of increasing the economic efficiency of work; the possibility of reducing risks through the use of neurotechnologies.

The philosophy of research ( management, production, trade) neurotechnologies gets its practical expression in the principles of neurotechnological activity in firms. Such principles of organizations reflect: the basic values of the organization; rules, techniques of neurotechnological activity. Therefore, the philosophy forms the organizational culture of neurotechnological activity of firms.

The principles of using research neurotechnologies can be described by analogy with the principles of marketing [36], p. 28 ].

Let us formulate the principles of the development of neurotechnologies:

- the principle of orientation (orientation) for the future. This principle is expressed in the advanced development of the methodology for designing neuro-technological technical means and equipment;

- the principle of focusing on solving problems (meeting needs). This principle is aimed at forming new needs of customers in such equipment and technologies. These needs must then be met through the application of new neurotechnologies;

- the principle of complexity of neurotechnological activity. This principle is expressed in a systematic combination of philosophy, methodology, and tools for designing products based on neurotechnologies;

- the principle of concentration of neurotechnological methods and / or technologies. This principle is that the integrated application of neurotechnologies should provide a new product quality. At the same time, the 
complex application of neurotechnologies should generate a synergistic effect in the activities of organizations;

- the principle of adaptability and flexibility in neurotechnological activity. This principle is related to the adaptation of the neurotechnological research system to the needs of clients;

- the principle of the program-target approach in the development of neurotechnologies. This principle ensures that resources are focused on achieving a certain goal in the field of neurotechnology development.

These principles can be the basis of the organizational culture of neuro-technological activity.

The organizational culture of the development of neurotechnologies (research, production, trade, management) will be considered: a set of beliefs; values; norms and stereotypes of employee behavior; a set of actions; characteristic reactions of the organization to external or internal challenges. This set of beliefs influences the methods of integration of employees in the process of their joint activities.

Organizational culture contributes to the implementation of the stated goals with the use of these types of neurotechnologies.

The level of development of neurotechnological engineering in the economy can be estimated by the following indicators:

- the percentage of nanotechnological goods and services in the total volume of mechanical engineering products of the sixth technological order;

- the percentage of annual growth in sales of neurotechnological services and goods in the total volume of mechanical engineering products of the sixth technological order, and others.

At the same time, the economic efficiency of using geotechnological methods of financial and economic activities of an organization that uses such technologies in its work can be determined using mathematical dependencies.

The increase in profit after the introduction of neuromarketing technologies in enterprises can be calculated using the following formula:

$\mathrm{Pnt}=\mathrm{A} * \mathrm{ROA} * \mathrm{Kr} * \mathrm{Kp} * \mathrm{Kt} * \mathrm{Km}$;

Where:

Pnt - the profit of the organization after the introduction of neurotechnologies in research, production, trade and management activities;

A- monetary value of the value of the assets of this organization;

ROA - return on assets of the organization;

$\mathrm{Kr}, \mathrm{Kp}, \mathrm{Kt}, \mathrm{Km}$; - coefficients whose value is greater than 1, reflecting an increase in the return on assets (an increase in the efficiency of the organization's activities) as a result of the introduction of neurotechnologies into the activities of this organization in the research, production, trade and management spheres.

\section{DISCUSSION}

In this article, the analysis of literary sources shows good prospects for the development of neurotechnologies. At the same time, it is possible to create a new segment in mechanical engineering - neurotechnological engineering.

However, while the development of neurotechnologies is not related by experts to the process of forming the sixth technological order.

In the article, a comparison was made: the tasks of the development of the sixth technological order; the tasks that are solved by neurotechnologies. This comparative analysis showed the proximity of the tasks to be solved. Therefore, there are reasons to include the development of neurotechnologies in the structure of the sixth technological order. We can say that the development of neurotechnologies (along with nanotechnology and other technologies) is an important structural element of the process of forming the sixth technological order.

Neurotechnologies can be applied at all stages of the life cycle (production, circulation, consumption) of goods and services. The further expansion of neurotechnologies to all new areas of social and economic activity will increase the market demand for neurotechnologies. Therefore, there will be an increasing demand for the 
development of the methodology for designing complexes of technical means for neurotechnological activities. The increase in demand for neuro-technological equipment will be the basis for the formation of neuro-technological engineering. Neuro-technological engineering will become a sub-branch in mechanical engineering and the economy of the sixth technological order.

The real directions of the use of neurotechnologies in the implementation of cargo transportation are considered in the work [29], p. 201-212].

The development of neurotechnological engineering will require the development of its legislative framework. Human rights must be taken into account. This is described in the works [25], p. 249-250; [29], p. 201-212; [30], p. 182-192].

An important structural segment of the nanotechnological development of the sixth technological order may be the expansion of the use of the methodology of the game approach (gamification) in educational technologies and professional training. Such neurotechnologies can be used in training the rational behavior of employees in crisis situations. The use of neurotechnologies in education can be aimed at increasing the psychological stability of employees in non-standard situations. Therefore, neurotechnologies can be considered as a way to reduce and limit the losses (damages) of organizations in dangerous situations.

The use of neurotechnologies to improve the efficiency of management in organizations was discussed in the article [30], p. 182-192].

The reason for the increased demand for neurotechnologies in the field of management is the cost of incorrect decisions in business processes.

It should be noted that at the beginning of the 21st century, the use of neurotechnologies in the design of new products (goods and services) is referred to as trade neuromarketing.

However, innovation and scientific research, development work (R \& D) act as a separate field of activity of machine-building design bureaus. This gives grounds to single out research neurotechnologies as an independent segment of neurotechnological development in mechanical engineering of the sixth technological order.

In 2021, it is possible to identify such practical areas of development of neurotechnologies: research neurotechnologies; production neurotechnologies; trade neurotechnologies; neurotechnologies in the field of management. At the same time, in the segment of managerial neurotechnologies, it is already possible to distinguish neurotechnologies in the field of planning, organization, motivation and control of activities in organizations.

It is possible to predict the spread of neurotechnologies in an ever-increasing number of spheres of human activity. Therefore, it is necessary to develop a methodology for analyzing the possibility of using neurotechnologies in any activity.

The methodology for studying the possibility of using neurotechnologies in a specific field of activity may consist of the following stages:

1) description of the technologies of a particular type of activity at the level of technological maps. The technological map is a sequence of descriptions of logically related operations when achieving the goal of the activity;

2) each of the operations included in the technological map is studied. They study the possibility of registering indications of nervous or biochemical reactions in the human body (employee, buyer);

3) if such a possibility of technical registration of human biochemical reactions exists, then they conclude that it is possible to use neurotechnologies;

4) in the absence of the possibility of technical registration of biochemical reactions of employees, a decision is made on the absence of the possibility of using neurotechnologies;

5) all operations of the employee are studied from the point of view of inappropriate actions of employees;

6) if such a possibility does not exist, then they conclude that it is possible to use neurotechnologies;

7) otherwise (there is no possibility of inappropriate actions), the absence of the possibility of using neurotechnologies in this technological process of the organization is also recognized;

8) for all operations in the technological map, check for the possibility of applying the game approach (gamification) in the process of learning how to perform this operation;

9) if such a possibility is detected, it should be recommended to use neurotechnologies;

10 ) if there is no possibility of gamification of the process of learning to perform operations, then the use of neurotechnologies is impossible; 
11) the analysis of the economic efficiency of the use of neurotechnologies in the technological process of the organization's activities is carried out;

12) if the use of neurotechnologies is recognized as economically effective, then the development of a project for the introduction of neurotechnologies in the technological process of the organization's activities is carried out;

13) the project for the introduction of neurotechnologies in the technologies of the organization's activities is practically being implemented;

14) the use of neurotechnologies in the organization is monitored;

15) the assessment of the real economic efficiency of the use of neurotechnologies in the organization is carried out.

During the implementation of this algorithm, the study of the possibility of using neurotechnologies should be taken into account: the existing specifics of the technological activity of the organization; the impact of these technologies on the behavior and psychology of employees of the organization.

In the interests of faster development of neurotechnologies, it may be recommended to: establish a public organization (association) of participants in neurotechnological research; create a neurotechnological platform (and/or cluster) in domestic mechanical engineering; create departments of neurotechnological engineering in industry universities, and so on.

Probably, the conversion of scientific knowledge in this field can contribute to the acceleration of the formation of a nanotechnology platform in post-industrial engineering of the sixth technological order.

An important element of the process of formation of neuro-engineering can be the development of scientific discussion on this topic. A comprehensive discussion of the prospects for the development of neurotechnologies can increase the efficiency of such development processes. At the same time, scientific discussion can reduce the risks of nanotechnology development in mechanical engineering.

At the same time, a neurotechnological scientific platform can be understood as a set of knowledge from various fields necessary for the successful development of neurotechnological engineering within the framework of the sixth technological order [37], [38], c. 55].

The development of neurotechnologies increases the potential for the development of other technologies of the sixth technological order (nanotechnologies, intelligent technologies, information technologies, digitalization technologies).

\section{CONCLUSION}

The research of scientific results in the field of neurotechnology development is carried out. The article substantiates the opinion that neurotechnologies should be considered as a structural element of the development of the sixth technological order, and predicts the expansion of the market niche for neurotechnological engineering. The paper develops the methodological provisions of the general theory of neurotechnologies. The paper adds the methodology, describes the functions and roles of the theory of neurotechnologies. The article offers criteria and mathematical formulas (model) for evaluating the economic efficiency of using neurotechnologies in the activities of organizations. The article proposes an algorithm for designing the neurotechnological development of organizations. It is proposed to establish a public organization of researchers in the field of neurotechnological machine building. The possibility of forming a neurotechnological platform and clusters is justified. All this will contribute to the development of neurotechnological engineering as part of the sixth technological order. An increase in the number of areas of activity that use the capabilities of neurotechnologies to increase the effectiveness of such activities is predicted.

\section{SOURCES OF FUNDING}

This research received no specific grant from any funding agency in the public, commercial, or not-for-profit sectors.

International Journal of Engineering Science Technologies 
Valery V. Glushchenko

\section{CONFLICT OF INTEREST}

The author have declared that no competing interests exist.

\section{ACKNOWLEDGMENT}

None.

\section{REFERENCES}

[1] Glushchenko V. V. Scientific theory of technological orderbs and research of directions of its practical application//Bulletin of Science and Practice. 2020. Vol. 6. No. 4. pp. 488-504. https://doi.org/10.33619/2414-2948/53/59

[2] Glazyev S. Yu. World economic structures in global economic develop-ment//Economics and Mathematical methods. 2016. Vol. 52. no. 2. pp. 3-29.

[3] Dyatlov S. A. Neural network technologies of innovative development: international experience//In the collection: Russia and St. Petersburg: Economy and Education in the XXI Century. XXXVIII scientific conference of the teaching staff, researchers and postgraduates on the results of the research activities of the Univer-sity for 2015. 2017. pp. 17-22.

[4] Dolinskaya A. Yu., Babanova Yu. V. The role of neurotechnologies in the development of the country's economy//In the collection: Science and innovation in the XXI century: current issues, discoveries and achievements. collection of articles of the VII International Scientific and Practical Conference: in 3 parts. 2017. pp. 244-247.

[5] Tkach T. V. From neuroscience to Neuroeconomics//In the collection: In-novative technologies in the cooperative educational process. materials of the inter-national correspondence scientific and practical conference dedicated to the 40th anniversary of the Saransk Cooperative Institute (branch) of the Russian University of Cooperation. 2016. pp. 71-75.

[6] Danilkina D. S. Neuroeconomics: a new interdisciplinary approach to the study of economic behavior. 2019. No. 3 (123). pp. 188-199.

[7] Kudryavtseva S. S. Nanotechnologies as a structure-forming factor of the sixth technological order in the open innovation model//Economics and manage-ment of innovative technologies. 2015. No. 4-1 (43). pp. 16-21.

[8] Zagidullina G. M., Sobolev E. A., Krylovsky A. B. Forecasting the struc-ture of the innovative sixth technological order and analyzing the priorities of cur-rent industrial development//Proceedings of the Kazan State University of Architec-ture and Civil Engineering. 2015. No. 1 (31). pp. 182-189.

[9] Tikhomirov N. N., Cherepanov K. A. Management of the development of high-tech enterprises in the conditions of the transition of the world economy to the sixth technological order//Economics and Entrepreneurship. 2015. No. 6-1 (59). pp. 729-734.

[10] Egorov N. E., Kovrov G. S., In Nikiforova.B. The main directions of technological development of the Republic of Sakha (Yakutia) in the transition to the sixth technological order//In the book: Innovative Clusters in the Digital Econ-omy: Theory and Practice in Proceedings of the VIII Scientific and Practical Con-ference with International Participation. Edited by A.V. Babkin. 2017. pp. 247-251.

[11] Yakovleva E. V. Management of the development of personnel intellec-tualization in business structures as a trend in the conditions of the formation of the economy of the sixth technological order//In the collection: Economics and man-agement of innovative processes, projects, programs/Materials of the International Correspondence Scientific and Practical Conference. 2015. pp. 84-86.

[12] Dorzhieva S. Ch. Neuroeconomics and neuromarketing as tools of mod-ern enterprise activity//Russian economic online magazine. 2018. No. 3. p. 30.

[13] Sazonov A. E. Neurotechnologies: present and future//Scientific and technical collection of the Russian Maritime Register of Shipping. 2009. No. 32. pp. 220-234.

[14] Chabanov V. A. The use of neurotechnologies to reduce the pilot's work-loads//Aviation systems. 2015. No. 3. pp. 43-47. 
[15] Abu-Abed F. N., Borisov N. A., Khabarov A. R. Application of neuro-technologies for the analysis of situations in the management of complex ob-jects//In the collection: Mathematical methods and information technologies in eco-nomics, sociology and education in the XVI International Scientific and Practical Conference: collection of articles. Edited by V. I. Levin. 2005. pp. 409-412.

[16] Zhukova (Borachuk) O. V., Shelepin Yu. E., Maksimova V. A., Ekimov P. A., Pronin S. V. Neurotechnologies and decision-making in conditions of uncer-tainty//In the collection: Technological Perspective within the Eurasian Space: new markets and points of economic growth 1st International Scientific Conference: conference proceedings. 2015. pp. 173-176.

[17] Korolkov A. P., Kolesnikov D. A., Khakhanov E. A. Prospects for the use of neurotechnologies for monitoring the state of oil trunk pipelines in the Arc-tic zone//Problems of risk management in the technosphere. 2016. No. 3 (39). pp. 6-12.

[18] Ovchinnikova V. A., Fomin V. A., Ivashov S. V. Prospects for the ap-plication of neurotechnologies in the production processes of new industry enter-prises//In the collection: Materials of conferences of the State Research Institute "NATIONAL DEVELOPMENT". DECEMBER 2016 Collection of selected arti-cles. The editorin-chief is Y. F. Elsesser. Responsible for the release of L. A. Pav-lov. 2016. pp. 82-85.

[19] Poskotinova L. V., Demin D. B. Transformations of biological and social feedback in the conditions of the development of neurotechnologies//Biomedical radio electronics. 2016. No. 5. pp. 21-23.

[20] Buzskaya 0. M. The potential of neurotechnologies in the formation of new orientations of the socio-cultural space//Law and practice. 2016. No. 4. pp. 183-187.

[21] Panasenko S. V., Kazantseva S. Yu. The role and significance of neuro-technologies in the digital economy//In the collection: Digital Economy and Educa-tion Moscow, 2018. pp. 35-38.

[22] Korolev A. A. Neurotechnologies as a factor in the formation of new in-dustries and the economy of Russia//In the collection: Foresight "Russia": new production for a new economy Collection of materials of the St. Petersburg Inter-national Economic Congress (SPEC-2016). 2016. pp. 393-400.

[23] Panasenko S. V., Mkrtchyan V. S. Prospects for the use of neurotech-nologies in various branches of the digital economy//Russian entrepreneurship. 2018. Vol. 19. no. 11. pp. 3269-3278.

[24] Bushmanova N. V. Introduction of neurotechnologies in education//In the collection: Goals and values of modern education Materials of the All-Russian Scientific and Practical Conference with International participation. Ed. by V. E. Chernik. 2019. pp. 205-207.

[25] Elyashevich A.M. Neurotechnologies. fantastic perspectives and real dangers//In the collection: Technological Perspective within the Eurasian Space: new Markets and Points of economic Growth Materials of the 2nd International Conference. 2016. pp. 249-250.

[26] Larina Yu. M. The place of the Russian Federation in the global market of neurotechnologies//Economics and Management: problems, solutions. 2019. Vol. 3. no. 3. pp. 14-18.

[27] Molchanov N. N., Muravyeva O. S., Galai N. I. Neurotechnologies: as-sessment of development prospects in Russia//Bulletin of the Udmurt University. Economics and Law series. 2019. Vol. 29. no. 2. pp. 142-151.

[28] Roadmap for the development of "end-to-end" digital technology (SCT) " Neurotechnologies and artificial intelligence»//R \& D Report/ Ministry of Digital Development, Communications and Mass Media of the Russian Federation, https://digital.gov.ru/uploaded/files/07102019ii.pdf (accessed 10.10.2019)

[29] Glushchenko V. V., Glushchenko I. I., Plakhotin E. O., Shinaeva A. I. Managerial neuromarketing in the sphere of services on railway transport [Elec-tronic resource] / / Molodezhny nauchny vestnik. 2017. No. 11 (24), pp. 201-212. URL: (http://www.mnvnauka.ru/2017/11/Glushchenko.pdf (17.11.2017).

[30] Glushchenko V. V., Glushchenko I. I. Development of methodology and practice directions of managerial neuromarketing//Bulletin of Science and Practice. 2018. Vol. 4. no. 3. pp. 182-192.

[31] Glushchenko V. V., Glushchenko I.I. Naukologiya as a methodological basis for improving the efficiency of the national innovation system//Online journal of Science Studies. 2015. Vol. 7. No. 1 (26). P. 5., ID DOI ID: 10.15862/65EVN115.

[32] Kotler F. Fundamentals of marketing: Trans. from English-M.: "Business book", " IMA-Cross. Plus", 1995 - $702 \mathrm{p}$.

[33] Langlois R. N., Kosgel M. M. Frank Knight on risk, uncertainty and the firm: New interpretation // Economic research. 
[34] Glushchenko V. V., Glushchenko I. I. Corporate risks of innovative en-trepreneurship in the context of the global crisis. M.: Economy and Entrepreneur-ship. 2014. No. 10. pp. 848-856.

[35] Glushchenko V. V., Glushchenko I. I. Analysis of risk factors affecting the financial result of an innovative project in high-tech mechanical engineering //Problems of Mechanical engineering and automation, 2014, no. 4 , pp.

[36] Knyshova E. N. Marketing. textbook. - M.: ID " FORUM»:INFRA-M, 2009, p. 13.

[37] Glushchenko V. V. Mechanical engineering as a conceptual basis for the formation of a scientific platform for mining engineering//International Conference on Innovations and Prospects for the Development of Mining Engineering and Electrical Engineering 2019, April 24-27, 2019, St. Petersburg Mining University, St. Petersburg, Russian Federation.:

https://iopscience.iop.org/issue/1755-1315/378/1

[38] Glushchenko V. V., Theory of technological orders. - M.: Glushchenko Valery Vladimirovich, 2020. - 80 p.

[39] Glushchenko V.V. (2021). Strategic planning of the transition of organ-izations to the sixth technological order in the national economy// International Journal of Engineering Sciences and Technologies, 5(1), 30 - 46. DOI: https://doi.org/10.29121/IJOEST.v5.i1.2021.159 